\title{
Analysis of 239 ordinary and severe cases of COVID-19: Clinical features and treatment
}

\author{
Susan Azizmohammadi (1), Sima Azizmohammadi (2), Sarah Dahmardeh (3), Hossein \\ Azargashb (1), Seyyed Javad Hosseini Shokouh (1), Mojgan Mohajeri-Iravani (4), \\ Maziar Mobasher (1), Saeed Soleiman-Meigooni (1), Mahdi Zabihi (1)
}

(1) Hajar Hospital, Aja University of Medical Science, Tehran, Iran; (2) Department of Gynecology, Hajar Hospital, AJA University of Medical Sciences, Tehran, Iran; (3) Medical Doctor, Tehran, Iran; (4) Department of Anesthesiology, Paramedical Faculty, Hajar Hospital, AJA University of Medical Sciences, Tehran, Iran.

This article is distributed under the terms of the Creative Commons Attribution Noncommercial License (CC BY-NC 4.0) which permits any noncommercial use, distribution, and reproduction in any medium, provided the original author(s) and source are credited.

\begin{abstract}
This study retrospectively analyzed the clinical characteristics of patients with new coronavirus infection (COVID-19) and summarizes the treatment experience. A total of 239 COVID-19 patients admitted to the Hajar Hospital, Aja University of Medical Science, Tehran, Iran from March 22, 2020 to May 18, 2020 were selected, including 176 cases in the ordinary group and 63 cases in the severe/critical group. We collected and compared the clinical data of the two groups of patients, including general conditions, clinical symptoms, signs, laboratory tests, lung CT imaging and prognosis, and analyzed the treatment plans of the two groups. The mean age of 239 COVID-19 patients was 48.1 17.6 years, including 132 males. Patients in the severe and critically ill groups were older than the normal group, with more males and more underlying diseases. The difference was statistically significant $(\mathrm{p}<0.05)$. The lymphocyte (LYM) counts and albumin (ALB) counts of the severe and critically ill groups were more significantly lower than those of the normal group; while the percentage of neutrophils (NEU), C-reactive protein (CRP), D-dimer, and lactate The increase of lactate dehydrogenase (LDH) and urea nitrogen (BUN) was more significant, and the difference was statistically significant $(p<0.05)$. Patients in the severe and critically ill groups received more antiviral drugs, glucocorticoids, and nasal catheters than those in the normal group, and the difference was statistically significant ( $\mathrm{p}<$ 0.05). Also, we observed that the most radiological finding was bilateral ground-glass opacity in both groups, however, the rate of typical abnormalities in both chest CT scan and chest x-ray was significantly higher in sever/critical group except air-bronchogram. Taken together, we showed that combination of oseltamivir and glucocorticosteroid such as dexamethasone was very effective in severe patients.
\end{abstract}

Key Words: COVID-19; clinical features; severity; imaging; laboratory test

Eur J Transl Myol 31 (3): 9579, 2021 doi: 10.4081/ejtm.2021.9579

The new coronavirus infection (COVID-19) is an acute respiratory disease caused by coronavirus 2 (SARS-CoV2) which is highly contagious and may result in severe pneumonia with an acute respiratory syndrome. The disease was discovered in Wuhan, Hubei Province in December 2019, and rapidly spread worldwide. At June 26, 2020, there were about 10 million confirmed cases worldwide and about 500,000 cases of death in total. According to the WHO report, about $13.8 \%$ of COVID19 patients represented a severe form and 6.1\% are critically ill patients. ${ }^{1-3}$ In addition, previous studies showed that patients might have rapid disease progression with poor prognosis and high mortality rate. ${ }^{4}$ Typical clinical manifestations of COVID-19 are mainly fever, chest tightness, cough and other respiratory symptoms, and severe patients can progress to dyspnea or even respiratory distress syndrome. It has been suggested that the main route of transmission is airborne transmission. Although reports are in contradirectry, there is evidence that COVID-19 could be transmitted through respiratory aerosols and gastreointestinal tract. ${ }^{5-}$ ${ }^{7}$ Although, the clinical manifestation of COVID-19 has been well documented in most regions and population, 
Table 1. Comparison of clinical characteristics of 239 COVID-19 patients in general and severe/critical group

\begin{tabular}{|c|c|c|c|c|}
\hline Age $(x \pm s)$ & $48.1 \pm 17.6$ & $43.9 \pm 14.5$ & $59.8 \pm 14.1$ & $<0.001$ \\
\hline \multicolumn{5}{|l|}{ Gender (n, \%) } \\
\hline Female (n, \%) & $107(44.7)$ & $90(50.9)$ & $16(25)$ & 0.032 \\
\hline Male (n, \%) & $132(55.3)$ & $86(49.1)$ & $47(75)$ & \\
\hline Close contact with confirmed cases (n, \%) & $194(81)$ & $144(81.8)$ & $50(79.2)$ & 0.972 \\
\hline \multicolumn{5}{|l|}{ Comorbidities (n, \%) } \\
\hline Hypertension (n, \%) & $48(20.3)$ & $16(9.1)$ & $32(50.8)$ & $<0.001$ \\
\hline Diabetes (n, \%) & 35 (14.5) & $13(7.3)$ & $22(34.9)$ & 0.386 \\
\hline Cerebrovascular disease (n, \%) & $9(3.8)$ & 0 & $9(14.3)$ & 0.026 \\
\hline Chronic kidney disease (n, \%) & $9(3.8)$ & $6(3.6)$ & $3(4.8)$ & $>0.99$ \\
\hline Chronic liver disease (n, \%) & $9(3.8)$ & $9(5.5)$ & 0 & 0.549 \\
\hline Coronary heart disease (n, \%) & $9(3.8)$ & $3(1.8)$ & $6(9.5)$ & 0.218 \\
\hline Malignant tumor (n, \%) & $3(1.3)$ & $3(1.8)$ & 0 & $>0.99$ \\
\hline Immunosuppressive (n, \%) & $3(1.3)$ & $3(1.8)$ & 0 & $>0.99$ \\
\hline COPD (n, \%) & $23(9.6)$ & 7 (3.9) & $16(25.4)$ & $<0.001$ \\
\hline No comorbidity (n, \%) & 157 (65.8) & $141(80)$ & $16(25.4)$ & $<0.001$ \\
\hline 1 comorbidity (n, \%) & $58(24.1)$ & $19(10.9)$ & 39(61.9) & \\
\hline 2 comorbidities (n, \%) & $15(6.3)$ & $13(7.3)$ & $2(3.2)$ & \\
\hline$\geq 3$ comorbidities $(\mathrm{n}, \%)$ & $9(3.8)$ & $3(1.8)$ & $6(9.5)$ & \\
\hline \multicolumn{5}{|l|}{ Symptoms (n, \%) } \\
\hline Fever $\geq 37.3^{\circ} \mathrm{C}(\mathrm{n}, \%)$ & $203(84.8)$ & $147(83.6)$ & 56 (88.9) & 0.921 \\
\hline Dry cough (n, \%) & $136(57)$ & $99(56.4)$ & 37 (58.7) & 0.871 \\
\hline Fatigue, muscle aches (n, \%) & $73(30.4)$ & $54(30.9)$ & $19(30.9)$ & 0.877 \\
\hline Dyspnea (n, \%) & 27 (11.4) & $16(9.1)$ & $11(17.5)$ & 0.555 \\
\hline Expectorant (n, \%) & 30 (12.7) & $22(12.7)$ & $8(12.7)$ & 0.734 \\
\hline Dizziness, headache (n, \%) & $18(7.6)$ & $6(3.6)$ & $12(19.0)$ & 0.121 \\
\hline Poor appetite (n, \%) & $15(6.3)$ & $10(5.5)$ & $5(7.9)$ & 0.985 \\
\hline Sore throat (n, \%) & $9(3.8)$ & $3(1.8)$ & $6(9.5)$ & 0.218 \\
\hline Diarrhea (n, \%) & $12(5.1)$ & $3(1.8)$ & $9(14.3)$ & 0.152 \\
\hline Vomiting (n, \%) & $23(9.6)$ & $12(6.8)$ & $11(17.5)$ & 0.831 \\
\hline Stomachache (n, \%) & $23(9.6)$ & $12(6.8)$ & $11(17.5)$ & 0.831 \\
\hline Onset of symptom to hospital admission & $5(4 \sim 8)$ & $5(4 \sim 7)$ & $6.5(4 \sim 10)$ & 0.018 \\
\hline \multicolumn{5}{|l|}{ Signs [median (IQR)] } \\
\hline Pulse [median (IQR)] & $85(79 \sim 92)$ & $86(80 \sim 92)$ & $82(74 \sim 93)$ & 0.096 \\
\hline Respiratory rate [median (IQR)] & $20(19 \sim 20)$ & $20(19 \sim 20)$ & $20(18 \sim 20)$ & 0.368 \\
\hline Systolic pressure $(\mathrm{x} \pm \mathrm{s})$ & $124.8 \pm 13.2$ & $121.2 \pm 9.5$ & $133.3 \pm 16.5$ & $<0.001$ \\
\hline Diastolic pressure $(\mathrm{x} \pm \mathrm{s})$ & $77.0 \pm 11.0$ & $74.2 \pm 9.5$ & $83.3 \pm 11.7$ & $<0.001$ \\
\hline Blood oxygen saturation [median (IQR)] & 97(93 98) & 97(96 98) & 91(89 93) & $<0.001$ \\
\hline
\end{tabular}

the main presentations of COVID-19 in Iraninan population have not been published widely. In this regard, we tried to share our experience and clinical manifestation of COVID-19 cases in Iran. Therefore, present study is aimed to evaluate and analyze the clinical characteristics of the COVID-19 patients in Iran, and summarize the treatment experience from them, and provide reference for clinicians on the front line of antiepidemic disease. In reaching this goal, we enrolled 239 admitted patients, including 63 severe cases. 
Table 2. Comparison of laboratory tests in patients with COVID-19 on admission to hospital.

\begin{tabular}{|c|c|c|c|c|}
\hline Item (unit, normal range) & $\begin{array}{l}\text { Overall(n=239), Median } \\
\text { (IQR) }\end{array}$ & $\begin{array}{l}\text { Ordinary group(n=176), } \\
\text { Median (IQR) }\end{array}$ & $\begin{array}{c}\text { Severe/critical } \\
\text { group(n=63), Median } \\
\text { (IQR) }\end{array}$ & p Value \\
\hline \multicolumn{5}{|l|}{ Blood routine } \\
\hline WBC $\operatorname{count}\left(\times 10^{9} \cdot \mathrm{L}^{-1}, \quad 3.5 \sim 9.5\right)$ & $5.4(4.1 \sim 6.8)$ & $4.9(4.0 \sim 5.9)$ & 6.5 (5.1 11.5) & 0.003 \\
\hline NEU\% (40 75) & $68.3(56.8 \sim 78.8)$ & $61.6(51.8 \sim 72.4)$ & $84.2(75.1 \sim 91.2)$ & $<0.001$ \\
\hline NEU count $\left(\times 10^{9} \cdot \mathrm{L}^{-1}, \quad 1.8 \sim 6.3\right)$ & $3.4(2.2 \sim 5.2)$ & $2.8(2.0 \sim 4.0)$ & $5.5(3.8 \sim 10.8)$ & $<0.001$ \\
\hline LYM \% (20 50) & 23.5 (13.3 34.2) & $28.0(20.4 \sim 37.4)$ & $9.9(6.4 \sim 19.3)$ & $<0.001$ \\
\hline LYM count $\left(\times 10^{9} \cdot \mathrm{L}^{-1}, \quad 1.1 \sim 3.2\right)$ & $1.1(0.7 \sim 1.5)$ & $1.3(0.9 \sim 1.7)$ & $0.7(0.4 \sim 1.1)$ & $<0.001$ \\
\hline $\operatorname{PLT}\left(\times 10^{9} \cdot \mathrm{L}^{-1}, \quad 125 \sim 350\right)$ & 164(133 218) & 163(140 216) & 182(129 227) & 0.717 \\
\hline \multicolumn{5}{|l|}{ Indicators of inflammation } \\
\hline CRP (mg. $\left.\mathrm{L}^{-1}, 0 \sim 8\right)$ & $13.6(3.7 \sim 34.1)$ & $5.6(0.8 \sim 21.4)$ & $36.9(19.3 \sim 96.1)$ & $<0.001$ \\
\hline PCT \&lt; 0.5, (n, \%) & $78.0(98.7)$ & $55.0(100)$ & $23.0(95.8)$ & 0.304 \\
\hline \multicolumn{5}{|l|}{ Coagulation } \\
\hline PT(s, 9.5 14.5) & $14.3(13.4 \sim 15.9)$ & $14.4(13.5 \sim 16.0)$ & $14.3(13.3 \sim 15.0)$ & 0.713 \\
\hline $\mathrm{D}$-Dimer $\left(\mu \mathrm{g} \cdot \mathrm{mL}^{\sim 1}, 0 \sim 1.1\right)$ & $0.22(0.14 \sim 0.35)$ & $0.19(0.09 \sim 0.26)$ & $0.45(0.22 \sim 0.64)$ & $<0.001$ \\
\hline \multicolumn{5}{|l|}{ Myocardial enzymes } \\
\hline $\mathrm{CK}\left(\mathrm{IU} \cdot \mathrm{L}^{-1}, 22 \sim 269\right)$ & $91.4(54.8 \sim 158.2)$ & 92.7 (55.5 154.4) & $86.2(46.0 \sim 178.1)$ & 0.543 \\
\hline CK-MB $\left(U \cdot L^{-11}, 0 \sim 25\right)$ & $11.1(9.5 \sim 15.7)$ & $11.3(9.4 \sim 15.8)$ & $11.1(9.6 \sim 13.6)$ & 0.598 \\
\hline $\mathrm{LDH}\left(\mathrm{U} \cdot \mathrm{L}^{-1}, 120 \sim 250\right)$ & $246(178 \sim 306)$ & 202 (169 270) & 295 (265 374) & $<0.001$ \\
\hline \multicolumn{5}{|l|}{ Biochemical indicators } \\
\hline $\operatorname{ALT}\left(\mathrm{IU} \cdot \mathrm{L}^{-1}, 9 \sim 50\right)$ & $23(15 \sim 42)$ & $20(15 \sim 35)$ & 29 (21 43) & 0.098 \\
\hline $\operatorname{AST}\left(I U \cdot L^{-1}, 15 \sim 45\right)$ & 27 (21 36) & 25 (21 35) & 40 (23 37) & 0.159 \\
\hline $\operatorname{ALB}\left(\mathrm{g} \cdot \mathrm{L}^{-1}, 40 \sim 55\right)$ & $42.4(38.3 \sim 46.9)$ & $44.3(41.2 \sim 47.7)$ & $36.3(33.0 \sim 39.1)$ & $<0.001$ \\
\hline $\mathrm{TB}\left(\mathrm{umol} \cdot \mathrm{L}^{-1}, \quad 3.4 \sim 21\right)$ & $16.4(11.8 \sim 21.1)$ & $14.7(11.4 \sim 20.1)$ & $17.2(12.9 \sim 21.3)$ & 0.263 \\
\hline $\mathrm{Cr}\left(\mathrm{umol} \cdot \mathrm{L}^{-1}, \quad 57 \sim 111\right)$ & $69(58 \sim 81)$ & $70(59 \sim 80)$ & $69(56 \sim 81)$ & 0.819 \\
\hline BUN $\left(\mathrm{mmol} \cdot \mathrm{L}^{-1}, \quad 3.1 \sim 8\right)$ & $4.0(3.0 \sim 5.4)$ & $3.6(3.0 \sim 4.5)$ & $5.4(4.3 \sim 6.0)$ & $<0.001$ \\
\hline
\end{tabular}

WBC: white blood cells, NEU: neutrophils, LYM: lymphocytes, PLT: platelets, CRP: C-reactive protein, PCT: procalcitonin, PT: prothrombin time, CK: creatine kinase, CK-MB: creatine kinase isoenzyme, LDH: lactate dehydrogenas, ALT: alanine aminotransferase, AST: aspartate aminotransferase, TB: total bilirubin, Cr: creatinine, BUN: urea nitrogen.

\section{Materials and Methods}

This study was a single-center, retrospective observational study and collected clinical data from 239 patients diagnosed with COVID-19 from March 22nd to May 18th, 2020. The collection and use of relevant information fully guarantee the privacy of patients and comply with ethical regulations. The study done accoriding the Declaration of Helsinki on human subjects. The ethical committee approved with protocol number(IR.AJAUMS.REC.1399.06) In this study, all cases have at leats one positive real-time fluorescence quantitative polymerase chain reaction (RT-PCR) for SARS-CoV-2 nucleic acid. ${ }^{8}$

\section{Patients groups}

We divided the COVID-19 patients in three subgoups:
1- Ordinary type: patients with mild symptoms such as low grade fever, cough, and etc.

2- Severe: patients with two of the following conditions (1) shortness of breath, respiratory rate $\geq 30 / \mathrm{min}$; (2) fingertip oxygen saturation $\leq 93 \%$ at rest; (3) arterial partial pressure of oxygen $(\mathrm{PaO} 2) /$ Fraction of inspiration oxygen $(\mathrm{FiO} 2) \leq 300 \mathrm{mmHg}(1 \mathrm{mmHg}=$ $0.133 \mathrm{kPa}$ ); (4) Pulmonary imaging showed significant progress of the lesion within 24 to $48 \mathrm{~h}$ $>50 \%$ was managed

3- Critical and severe: patients consistent with one of the following conditions: A) Respiratory failure occurrred and mechanical ventilation was required; B) Shock occured; C) Combining other organ failures required ICU monitoring treatment. 
Table 3. Comparison of laboratory tests in patients with COVID-19 on admission to hospital

\begin{tabular}{|c|c|c|c|c|}
\hline Item (unit, normal range) & Overall $(n=207)$ & $\begin{array}{l}\text { Ordinary group } \\
(n=144)\end{array}$ & $\begin{array}{l}\text { Severe/critical } \\
\text { group }(n=63)\end{array}$ & $p$ Value \\
\hline \multicolumn{5}{|l|}{ Chest CT abnormalities } \\
\hline Any typical abnormalities & 191 (92.3\%) & 129 (89.6\%) & $62(98.4 \%)$ & 0.003 \\
\hline Consolidation & $41(19.8 \%)$ & $33(22.9 \%)$ & $8(12.9 \%)$ & $<0.001$ \\
\hline Ground-glass opacity & $89(43.0 \%)$ & $71(49.3 \%)$ & $18(29.0 \%)$ & $<0.001$ \\
\hline $\begin{array}{l}\text { Mixed ground-glass opacity and } \\
\text { consolidation }\end{array}$ & $38(18.4 \%)$ & $6(4.2 \%)$ & $32(51.6 \%)$ & $<0.001$ \\
\hline Crazy-paving pattern & $22(10.6 \%)$ & $20(13.9 \%)$ & $2(3.2 \%)$ & $<0.001$ \\
\hline Air bronchogram & $29(14 \%)$ & 8 (5.6\%) & 21 (33.9\%) & 0.717 \\
\hline Bilateral involvement & $163(78.7 \%)$ & $101(70.1 \%)$ & $62(98.4 \%)$ & $<0.001$ \\
\hline Peripheral distribution & 125 (60.4\%) & $95(66.0 \%)$ & $30(48.4 \%)$ & $<0.001$ \\
\hline Isolated lower lobe involvement & $51(24.6 \%)$ & $40(27.8 \%)$ & $11(17.7 \%)$ & $<0.001$ \\
\hline Chest X-ray abnormalities & Overall (n=88) & $\begin{array}{l}\text { Ordinary group } \\
\quad(\mathrm{n}=57)\end{array}$ & $\begin{array}{l}\text { Severe/critical } \\
\text { group }(n=31) \text {, }\end{array}$ & P Value \\
\hline Any typical abnormalities & $81(92.0 \%)$ & $53(93.0 \%)$ & $28(90.3 \%)$ & $<0.001$ \\
\hline Consolidation & $13(14.8 \%)$ & $3(5.2 \%)$ & $10(32.3 \%)$ & $<0.001$ \\
\hline Ground-glass opacity & $21(23.9 \%)$ & $10(17.5 \%)$ & $11(35.5 \%)$ & $<0.001$ \\
\hline Bilateral involvement & $78(88.6 \%)$ & $54(94.7 \%)$ & $31(100 \%)$ & 0.561 \\
\hline Peripheral distribution & $7(8.0 \%)$ & $4(7.0 \%)$ & $3(9.7 \%)$ & 0.341 \\
\hline Isolated lower lobe involvement & $11(12.5 \%)$ & $5(8.8 \%)$ & $6(19.4 \%)$ & $<0.001$ \\
\hline
\end{tabular}

\section{Data collection}

The relevant data was collected and obtained through the in-hospital electronic medical record system, which was summarized in an electronic format and reviewed by senior physicians. The information collected included demographic data, previous medical history, history of epidemic exposure, clinical symptoms and signs, laboratory tests, chest imaging findings, treatment measures, and prognosis. The laboratory tests at least included: blood routine, CRP, PCT, prothrombin time (PT), D-dimer, creatine kinase $(\mathrm{CK})$, creatine kinase isoform Enzymes (CK-MB), LDH, alanine aminotransferase (ALT), aspartate aminotransferase (AST), serum albumin (ALB), total bilirubin (TB), creatinine $(\mathrm{Cr})$, and BUN. The laboratory examination data of ordinary patients were collected within 48 hours of admission, and the severe and critically ill patients were collected within 48 hours of admission to the intensive care unit. The statistical content of treatment measures included the application of antiviral drugs, antibacterial drugs, glucocorticoids, oxygen therapy and respiratory support.

\section{Statistics}

All statistical analyses were performed by using SPSS 25.0 software, the t-test and chi-square test were used to compare the mean of two groups of samples. The measurement data of normal distribution is represented by mean $(\overline{\mathrm{x}}) \pm \mathrm{SD}$; p value under 0.05 was consider as a significance level.

\section{Results}

\section{General information}

Table 1 shows the general data of 239 COVID-19 patients collected in this study. The average age of the patients was $48.1 \pm 17.6$ years. Among them, 132 were male (55.3\%) and 107 were female (44.7\%). In terms of disease susceptibility, there was no statistically significant difference between men and women $(\mathrm{p}=$ 0.42 ), but men were more likely to develop severe pneumonia (47 cases ( $75 \%$ ) vs 16 cases (25\%), $\mathrm{P}=0.032$ ). Compared with the common type, patients with severe and critically ill patients are older [ $(59.8 \pm 14.1)$ years vs (43.9 \pm 14.5$)$ years, $p<0.001]$, and previously had hypertension [32 cases (50.8\%) vs 16 cases ( $9.1 \%)$, p < 0.001 ] and cerebrovascular diseases [9 cases (14.3\%) vs 0 cases, $p=0.026]$, and the number of underlying diseases of previous diseases was higher than that of the ordinary group ( $p<0.001)$. Other indicators such as contact history, onset symptoms, pulse, breathing frequency and other indicators showed no significant differences (all $\mathrm{p}>0.05$ ).

\section{Laboratory findings}

Table 2 shows the comparison of laboratory examination items between 63 severe /critically ill patients and 176 ordinary patients. In blood tests and 26 patients (11.0\%), 
Table 4. Treatments of Patients Infected With SARS-CoV-2

\begin{tabular}{|c|c|c|c|c|}
\hline & $\operatorname{Overall}(n=239)(n, \%)$ & $\begin{array}{l}\text { General group } \\
(n=176)(n, \%)\end{array}$ & $\begin{array}{c}\text { Severe and } \\
\text { critical group } \\
(n=63)(n, \%)\end{array}$ & $p$ Value \\
\hline \multicolumn{5}{|l|}{ Antiviral therapy } \\
\hline Oseltamivir & $239(100)$ & $176(100)$ & $63(100)$ & \\
\hline Lopinavir & $44(18.4)$ & $12(6.8)$ & $32(50.7)$ & $<0.001$ \\
\hline No antiviral drug & 0 & 0 & 0 & \\
\hline \multicolumn{5}{|l|}{ Other treatments } \\
\hline Hydroxychloroquine & $188(78.6)$ & $143(81.25)$ & $45(71.4)$ & 0.238 \\
\hline Antibiotic* & $148(62)$ & 105 (59.6) & $33(52.4)$ & 0.346 \\
\hline Glucocorticoid & $78(32.9)$ & $34(19.4)$ & $44(69.8)$ & $<0.001$ \\
\hline \multicolumn{5}{|l|}{ Supportive therapy } \\
\hline Intranasal oxygen inhalation & $121(50.6)$ & $61(34.5)$ & $60(95.8)$ & $<0.001$ \\
\hline High flow oxygen & $13(5.4)$ & 0 & $13(20.6)$ & $<0.001$ \\
\hline Non-invasive and invasive mechanical ventilation & $8(3.3)$ & 0 & $8(12.7)$ & $<0.001$ \\
\hline
\end{tabular}

86 patients (36.4\%), 41 patients (17.4\%), and 184 patients (77.9\%) had elevated white blood cell counts, NEU\%, NEU absolute value, and CRP, respectively in ordinary and severe/critically ill patients. In addition, we observed that 44 patients (18.6\%), 117 patients (49.6\%), and 45 patients $(19.1 \%)$ were accompanied by a decrease in the total number of white blood cells, the absolute value of LYM, and platelets (PLT), respectively in both groups. Also, 96 patients (40.7\%), 72 patients (30.5\%), and 9 patients (3.8\%) had increased or prolonged PT, APTT, and D-dimer, respectively in both groups; 28 cases $(11.9 \%), 14$ cases (5.9\%), and 117 cases (49.6\%) were accompanied by increased CK, CK-MB, and LDH. In the biochemical examination, 36 patients (15.2\%), 27 patients (11.4\%), 60 patients (25.5\%), 12 patients (5.1\%), 9 patients (3.8\%) developed ALT, AST, TB, Cr, BUN increased and ALB decreased in 93 cases (39.3\%). During routine blood tests, the total number of white blood cells in the ordinary group $\left[4.9(4.0 \sim 5.9) \times 10^{9} \mathrm{~L}\right.$ ${ }^{1}$ vs $\left.6.5(5.1 \sim 11.5) \times 10^{9} \mathrm{~L}^{-1}, \mathrm{p}=0.003\right]$, NEU\% [61.6\% ( 51.8 72.4) vs 84.2\%(75.1 91.2), p <0.001] and absolute value $\left[\begin{array}{llllll}2.8 & (2.0 \sim 4.0) \times 10 & 9 & L^{-1} & \text { vs }\end{array}\right.$ 5.5(3.8 10.8) $\left.\times 10^{9} \mathrm{~L}^{-1}, \mathrm{p}<0.001\right]$ significantly lower than the heavy and critical groups; the percentage of LYM in the heavy and critical groups [9.9\% (6.4 19.3) vs $28 \%(20.4 \sim 37.4), \mathrm{p}<0.001$ ] and the absolute value [0.7(0.4 1.1) $\times 10^{9} \mathrm{~L}^{-1}$ vs $1.3(0.9 \sim 1.7) \times 10^{9} \mathrm{~L}^{-1}, \mathrm{p}<$ $0.001]$ significantly lower than the normal group. CRP [36.9(19.3 96.1)mg. $\mathrm{L}^{-1}$ vs 5.6(0.8 21.4)mg. $\mathrm{L}^{-1}$, $\mathrm{p}<$ $0.001], \quad \mathrm{D}$ dimer $\left[0.45(0.22 \sim 0.64) \quad \mu \mathrm{g} \cdot \mathrm{mL} \quad{ }^{-1} \quad \mathrm{vs}\right.$ $\left.0.19(0.09 \sim 0.26) \mu \mathrm{g} \cdot \mathrm{mL}^{-1}, \mathrm{p}<0.001\right]$, and $\mathrm{LDH}$ [295(265 374) U. $\mathrm{L}^{-1}$ vs 202(169 270) U. $\mathrm{L}^{-1}$, p < $0.001], \mathrm{p}=0.001$ ] detection value was significantly higher than that of normal group patients. The ALB detection value of the heavy and critical groups was significantly lower than that of the normal group [36.3(33.0 39.1) $\mathrm{g} \cdot \mathrm{L}^{-1}$ vs 44.3(41.2 47.7) $\mathrm{g} \cdot \mathrm{L}^{-1}$, p < 0.001]. There was no significant difference in $\mathrm{Cr}$ detection value between the two groups ( $\mathrm{p}=0.819$ ); BUN increased more significantly in severe and critically ill patients $\left[5.4(4.3 \sim 6.0) \mathrm{mmol} \mathrm{L}^{-1}\right.$ vs $3.6(3.0 \sim 4.5)$ mmol L ${ }^{-1}$ ] $(\mathrm{p}<0.001)$, but the mean is still within normal range.

\section{Comparison of lung CT changes}

Among 236 patients. 207 patients were undergoing lung CT examination and 88 patients were undergoing chest X-ray upon admission. 207 patients had lung CT imaging on admission, including patients 144 (81.8\%) in ordinary patients and 63 patients (100\%) in severe patients with CT imaging changes in the lungs. In addition, among 88 patients with chest X-ray evaluation, 57 patients (32.3\%) was placed into ordinary group and 31 patients (49.2\%) were severe/critically ill patients. Table 3 shows the detailed findings of chest X-ray and chest CT examination in ordinary and severe/critically ill patients. There was no statistically significant difference between the groups. The lung CT signs of the diagnosed cases are summarized as follows: Most patients with lung CT usually show single or multiple ground glass shadows, and consolidations. Our results showed that the most prevalent chest CT feature was ground-glass opacity (43.0\%) with bilateral involvement pattern (78.7\%) and followed by consolidation and peripheral distribution. Severe/critically ill patients had a significant higher rate of abnormalities, including ground-glass opacity, consolidation, crazy-paving pattern $(p<0.001)$. Only airbronchogram was not significantly differ among two 
groups. In addition, the same results were seen in chest X-ray (Table 3).

\section{Treatment and prognosis}

Table 4 shows that all patients received one or more treatment, including 239 cases of oseltamivir (100\%) and 44 cases of lopinavir (18.4\%). Patients in the severe and critically ill groups received significantly more antiviral drugs than the general group ( $\mathrm{p}<0.001$ ). More than $50 \%$ of patients in both groups used antibacterial drugs, mainly including azithromycin and levofloxacin. Glucocorticoids in severe and critically ill patients [44 cases $(69.8 \%)$ vs 34 cases $(19.4 \%), p<0.001]$. The rate of nasal catheters and high flow oxygen inhalation is also higher ( $\mathrm{p}<0.001,0.026)$. In this study, five critically ill patients died of acute respiratory distress and other patients were discharged from the hospital.

\section{Discussion}

The initial reports on the SARS-CoV-2 and COVID-19 believed that they were similar to the SARS and MERS coronaviruses that occurred in the early years. Most infected patients showed fever, dry cough, fatigue, and dyspnea. ${ }^{3,9,10}$ This study also confirmed that fever and dry cough accounted for $84.8 \%$ and $57.0 \%$ of the patients' onset symptoms, respectively. The other onset symptoms also included fatigue, muscle aches, difficult breathing, dizziness, headache, and diarrhea. However, we observed that fewer patients started with typical upper respiratory symptoms, such as runny nose, sneezing, swollen throat, etc., which is different from the previously reported symptoms related to SARS and MERS. ${ }^{3}$ Earlier reports showed that the new coronavirus is more susceptible to men, which may be related to the 99 patients included are mostly male workers in Wuhan South China Seafood Market. ${ }^{11}$ The ratio of men to women in this study is $1: 0.81$, but there is no statistical difference, so there is insufficient evidence to prove that men are more susceptible to COVID-19. However, we found that men account for a higher proportion of severe and critically ill patients, which means that men are more likely to develop severe and critically pneumonia. This study also found that severe and critically ill patients often have more comorbid diseases, which mainly include hypertension and cerebrovascular diseases, suggesting that these past medical histories may be a risk factor for severe and critically ill patients. According to the analysis of the duration of time from onset to admission of the two groups of patients, the time between the onset and admission to hostital of patients in the heavy and critically ill groups is significantly longer than that of ordinary patients, which also provides us with inspiration for disease prevention and control: suspected cases should be diagnosed and detected early, early isolation, early diagnosis, early treatment, to avoid the conversion of some ordinary patients to heavy and critical due to delayed diagnosis and treatment. Laboratory analysis shows that many indicators are significantly different between the patients in the severe and critical group and the normal group. We observed that the absolute value of NEU, NEU\%, and CRP were more significantly increased in patients with severe and critically ill patients; and the percentage and absolute value of lymphocytes of LYM\% were also more significantly decreased than those of ordinary type. Changes in these indicators indicate that the mechanism of COVID-19 development may be similar to pneumonia caused by SARS and MERS coronavirus, and there may be a process of cellular immune impairment. ${ }^{4}$ SARS-CoV-2 infection also has a certain impact on the coagulation system. Some patients have prolonged PT, APTT, and severe and critically ill patients. The D-dimer increase is more obvious than the normal type. At the same time, we also observed that lactate dehydrogenase (LDH) was significantly higher in patients with severe and critically ill patients than in the normal group, which indicates that the virus may directly or indirectly damage cardiomyocytes through cytokine storms. The reduction of ALB levels is particularly obvious in severe and critically ill patients. It is speculated that it may be related to the liver albumin synthesis disorder caused by the direct damage of the virus to liver cells. In addition, increased body consumption due to inflammation, fever, etc. can also lead to low ALB. Although the vast majority of patients did not have obvious renal impairment and their BUN values were within the normal range, the BUN levels of patients in the severe and critical group were still generally higher than those in the normal group, which may be more severe than the former. Fever caused by high metabolism. In conclusion, SARS-CoV-2 infection has adverse effects on multiple organs and systems, including the coagulation system, heart, liver, and kidneys, and the specific damage mechanism requires further pathophysiology for the pathogenicity of the virus the study. Anti-viral drugs is particularly important in the treatment of coronavirus, but there is still no specific drug for coronavirus infection. ${ }^{12}$ In this study, all patients received oseltamivir antiviral therapy. We showed that combination of oseltamivir and glucocorticosteroid such as dexamethasone was very effective in severe patients. However, statistuical analysis failed to show the effectiveness of this treatment in criticaly ill patients. In view of previous reports that SARS-CoV, MERS-CoV, and SARS-CoV-2 infections can induce cytokine storms, ${ }^{3}$ glucocorticoids are often used to treat severely ill patients and can benefit by reducing lung damage caused by inflammation. However, there are also studies that the application of glucocorticoids does not significantly improve the prognosis. ${ }^{13}$ In conclusion, Taken together, our data reported that five critically ill patients died of acute respiratory distress and other patients were discharged from the hospital. Elderly patients with multiple cardiovascular and cerebrovascular diseases are more prone to severe and critical COVID-19, and often have abnormalities in multiple organs or systems.Totally, we 
showed that combination of oseltamivir and glucocorticosteroid such as dexamethasone was very effective in severe patients. Clinicians should make timely decisions based on clinical symptoms, signs and laboratory examination results judge and adjust the treatment plan.

\section{List of acronyms}

ALB - albumin

ALT - alanine aminotransferase

AST - aspartate aminotransferase

BUN - urea nitrogen

CK - creatine kinase

CK-MB - creatine kinase isoform enzymes

COVID-19 - new coronavirus infection

$\mathrm{Cr}$ - creatinine,

CRP - C-reactive protein

FiO2 - Fraction of inspiration oxygen

ICU - intensive care unit

LDH - lactate dehydrogenase

LYM - lymphocyte

NEU - neutrophils

$\mathrm{PaO} 2$ - partial pressure of oxygen

PLT - platelets

PT - prothrombin time

RT-PC - real-time fluorescence quantitative polymerase chain reaction

SARS-CoV-2 - severe acute respiratory syndrome coronavirus 2

TB - total bilirubin

\section{Authors contributions}

SuZ, SiZ, SD, HA, SJHS, MMI, MM, SSM, and MZ contributed to the research concept and study design, literature review, data collection, statistical analyses, data interpretation, manuscript writing and review.

Acknowledgments None

\section{Funding None}

\section{Conflict of Interest}

The authors declare no conflicts of interest.

\section{Ethical Publication Statement}

We confirm that we have read the Journal's position on issues involved in ethical publication and affirm that this report is consistent with those guidelines.

\section{Corresponding Author}

Sarah Dahmardeh, Pasteur Institute of Iran,Tehran, Iran. ORCID iD: 0000-0002-0015-2819

Sarah Dahmardeh: sarahdahmardeh@gmail.com

E-mails and ORCID iD of co-authors

Susan Azizmohammadi: dr.azizmohamadi@gmail.com ORCID ID:0000-0001-7364-1253

Sima Azizmohammad: simaazizmohammadi@yahoo.com ORCID ID:0000-0003-0560-0497
Hossein Azargashb: H_Azargashb@yahoo.com ORCID iD: 0000-0003-1371-1971

Seyyed Javad Hosseini Shokouh:

ORCID iD: 0000-0002-13292-1736

$$
\text { sj.hoseini@ajaums.ac.ir }
$$

Mojgan Mohajeri-Iravani:

$$
\text { mojganmoon23001@gmail.com }
$$

ORCID iD: 0000-0001-8279-6273

Maziar Mobasher:

mobashermaziar.icm@gmail.com

ORCID iD: 0000-0001-6677-8235

Saeed Soleiman-Meigooni:

ORCID ID: 0000-0001-5641-7380

$$
\text { dr.saeed.meigooni@gmail.com }
$$

Mahdi Zabihi: Zabihi.nurse@gmail.com

ORCID iD: 0000-0003-1743-8546

\section{References}

1. Bogoch II, Watts A, Thomas-Bachli A, Huber C, Kraemer MUG, Khan K. Potential for global spread of a novel coronavirus from China. J Travel Med. 2020 Mar 13;27(2):taaa011. doi: 10.1093/jtm/ taaa011.

2. National Health Commission of the People's Republic of China. The latest situation of the new coronavirus pneumonia epidemic situation as of 24:00 on February 18. [EB/OL].[2020-02-19]

3. Shang Y, Pan C, Yang X, Zhong M, Shang X, Wu Z, Yu Z, Zhang W, Zhong Q, Zheng X, Sang L, Jiang L, Zhang J, Xiong W, Liu J, Chen D. Management of critically ill patients with COVID19 in ICU: statement from front-line intensive care experts in Wuhan, China. Ann Intensive Care. 2020 Jun 6;10(1):73. doi: 10.1186/s13613-020-00689-1.

4. Huang C, Wang Y, Li X, Ren L, Zhao J, Hu Y, Zhang L, Fan G, Xu J, Gu X, Cheng Z, Yu T, Xia J, Wei Y, Wu W, Xie X, Yin W, Li H, Liu M, Xiao Y, Gao H, Guo L, Xie J, Wang G, Jiang R, Gao Z, Jin Q, Wang J, Cao B. Clinical features of patients infected with 2019 novel coronavirus in Wuhan, China. Lancet. 2020 Feb 15;395(10223):497-506. doi: 10.1016/S0140-6736(20)30183-5. Epub 2020 Jan 24. Erratum in: Lancet. 2020 Jan 30.

5. Wang D, Hu B, Hu C, Zhu F, Liu X, Zhang J, Wang B, Xiang H, Cheng Z, Xiong Y, Zhao Y, Li Y, Wang X, Peng Z. Clinical Characteristics of 138 Hospitalized Patients With 2019 Novel Coronavirus-Infected Pneumonia in Wuhan, China. JAMA. 2020 Mar 17;323(11):1061-1069. doi: 10.1001/jama.2020.1585. Erratum in: JAMA. 2021 Mar 16;325(11):1113.

6. Chan JF, Yuan S, Kok KH, To KK, Chu H, Yang J, Xing F, Liu J, Yip CC, Poon RW, Tsoi HW, Lo SK, Chan KH, Poon VK, Chan WM, Ip JD, Cai JP, Cheng VC, Chen H, Hui CK, Yuen KY. A familial cluster of pneumonia associated with the 2019 novel coronavirus indicating person-to-person transmission: a study of a family cluster. Lancet. 
2020 Feb 15;395(10223):514-523. doi: 10.1016/ S0140-6736(20)30154-9. Epub 2020 Jan 24.

7. Ren LL, Wang YM, Wu ZQ, Xiang ZC, Guo L, Xu T, Jiang YZ, Xiong Y, Li YJ, Li XW, Li H, Fan GH, Gu XY, Xiao Y, Gao H, Xu JY, Yang F, Wang XM, Wu C, Chen L, Liu YW, Liu B, Yang J, Wang XR, Dong J, Li L, Huang CL, Zhao JP, Hu Y, Cheng ZS, Liu LL, Qian ZH, Qin C, Jin Q, Cao B, Wang JW. Identification of a novel coronavirus causing severe pneumonia in human: a descriptive study. Chin Med J (Engl). 2020 May 5;133(9):1015-1024. doi: 10.1097/CM9.0000000000000722.

8. Chen Y, Liu Q, Guo D. Emerging coronaviruses: Genome structure, replication, and pathogenesis. J Med Virol. 2020 Apr;92(4):418-423. doi: 10.1002/jmv.25681. Epub 2020 Feb 7. Erratum in: J Med Virol. 2020 Oct;92(10):2249.

9. Lee N, Hui D, Wu A, Chan P, Cameron P, Joynt GM, Ahuja A, Yung MY, Leung CB, To KF, Lui SF, Szeto CC, Chung S, Sung JJ. A major outbreak of severe acute respiratory syndrome in Hong Kong. N Engl J Med. 2003 May 15;348(20):198694. doi: 10.1056/NEJMoa030685. Epub 2003 Apr 7.

10. Assiri A, Al-Tawfiq JA, Al-Rabeeah AA, AlRabiah FA, Al-Hajjar S, Al-Barrak A, Flemban H,
Al-Nassir WN, Balkhy HH, Al-Hakeem RF, Makhdoom HQ, Zumla AI, Memish ZA. Epidemiological, demographic, and clinical characteristics of 47 cases of Middle East respiratory syndrome coronavirus disease from Saudi Arabia: a descriptive study. Lancet Infect Dis. 2013 Sep;13(9):752-61. doi: 10.1016/S14733099(13)70204-4. Epub 2013 Jul 26.

11. Chen N, Zhou M, Dong X, Qu J, Gong F, Han Y, Qiu Y, Wang J, Liu Y, Wei Y, Xia J, Yu T, Zhang $\mathrm{X}$, Zhang L. Epidemiological and clinical characteristics of 99 cases of 2019 novel coronavirus pneumonia in Wuhan, China: a descriptive study. Lancet. 2020 Feb 15;395(10223):507-513. doi: 10.1016/S01406736(20)30211-7. Epub 2020 Jan 30.

12. de Wit E, van Doremalen N, Falzarano D, Munster VJ. SARS and MERS: recent insights into emerging coronaviruses. Nat Rev Microbiol. 2016 Aug;14(8):523-34. doi: 10.1038/nrmicro.2016.81. Epub 2016 Jun 27.

Submission: December 31, 2020 Revision received: April 28, 2021 Accepted for publication: April 29, 2021 